\title{
A Prospective Screening of Gene Copy Number Variation in Brazilian Admixed Population Sample
}

\author{
Dianny Elizabeth Jimenez ${ }^{1}$, Tulio Cesar de Lima Lins ${ }^{2}$, Priscilla Orosco Taveira ${ }^{1}$, Rinaldo Wellerson Pereira ${ }^{1}{ }^{2 *}$ \\ ${ }^{1}$ Programa de Pos-Graduaçao em Ciencias Genomicas e Biotecnologia, Universidade Catolica de Brasilia, Brasilia, DF, Brazil \\ ${ }^{2}$ Programa de Pos-Graduacao em Patologia Molecular, Universidade de Brasilia, Brasilia, DF, Brazil
}

\begin{abstract}
Copy number variants (CNVs) represent an important source of variation in the human genome. Some CNVS embedded genes are differently distributed among the human population groups. Therefore, it is important to understand the distribution of CNV within and between populations, especially in those with admixed ancestry, such as the Brazilians. The aim of the study was to investigate the variability of a set of CNV-embedded genes in a sample of the Brazilian population. The CNV-embedded genes were chosen based on data showing that they have differential copy variation distribution between African and Europeans. Four genes (POLR2J4, PCDHB13, NPEPPS and AMY1) were investigated by qPCR in a sample of 96 Brazilians, previously classified by genetic ancestry. The gene AMY1 showed a variable copy numbers in the range of 1 to 8 copies whereas NPEPPS ranged from 1 to 5 copies. A low variability was identified for the POLR2J4 and PCDHB13 genes, showing 2 copies in frequency of 0.875 and 0.917 , respectively. Genetic ancestry was not correlated to the number of copies of the AMY1and NPEPPS genes. The results provided an overview of the corresponding frequency of gene copy number variation in a sample of the Brazilian population, serving as reference for further genetic population studies, which may correlate these polymorphisms with other phenotypic features.
\end{abstract}

\section{Keywords: qPCR; CNV; POLR2J4; PCDHB13; NPEPPS; AMY1}

\section{Introduction}

Copy number variations (CNVs) are deletions or duplications of DNA segments of at least 1000 bases $(1 \mathrm{~kb})$ up to several $\mathrm{Mb}$ in size present in a variable range of copy numbers when compared to a reference genome [1-4]. Their occurrence is variable among human populations, making them a wide source of population differentiation [5-7]. Copy number polymorphisms (CNPs) are CNVs with population frequencies of at least $1 \%[8-12]$

CNVs play an important role over several genetic diseases susceptibility, such as obesity, diabetes, cancer and neuropsychiatric diseases [7,11-14]. In addition, the genetic heritability of nonpathological human traits can also be explained by CNVs [15-18]. For instance, adaptive evolution on chemosensation and immune response [19]. Patterns of copy number in salivary amylase gene have also a correlation with human populations with different dietary history, revealing an evolutionary selection for copy numbers in cultures with higher starch diets [20]. Thus, CNV may have exerted an important role in the evolution of physiological adaptations modeling the stratification of continental populations [2]. The literature describes CNVs loci showing significant copy number differences between different ethnic groups [14,21-24], including some that are population-specific $[25,26]$.

The use of Ancestry-Informative markers (SNPs and Indels polymorphism) has long been used to evaluate population stratification and admixture. It has been used to depict the Brazilian population as one of high heterogeneity, characterized by varying admixture from parental populations, such as European, African and Native Americans [27-29]. However, studies conducted in the Brazilian population evaluated CNV only as a source of pathological variation and, up to the moment, no investigation considered general population samples as a source of phenotypic variation, especially relating CNVs and genetic ancestry. In order to determine the polymorphism degree in individuals from the Brazilian population, this study aimed to assess the copy number of the CNVs embedded genes AMY1, NPEPPS, $P C D H B 13$ and POLR2J4 described as differently distributed among European and African population.

\section{Material and Methods \\ Samples}

The study analyzed DNA samples from 96 (51 men and 45 women) unrelated Brazilians. The European, African and Native American genetic ancestry proportions were previously estimated in the sample with 28 ancestry informative markers [28]. DNA from peripheral blood was extracted by a saline precipitation method, and the concentration and quality were determined with NanoDrop ${ }^{\circ}$ ND-1000 Spectrophotometer (Thermo Scientific, USA). A unique sample with a high quantity DNA was selected as a calibrator sample for quality control in all qPCR reactions. All samples were taken with the knowledge and consent of the donors, and the Ethic Committee of Universidade Catolica de Brasilia approved the research protocol.

\section{Copy number polymorphism estimation}

The four selected genes (AMY1, NPEPPS, PCDH-BETA13 and $P O L R 2 J 4)$ are within $\mathrm{CNV}$ regions that were recognized as polymorphic, and their copy numbers were differently distributed in representative populations of European, African and Asian ancestry in a previous study [7] and structural variants were accessed in the Database of Genomic Variants (DGV, http://dgv.tcag.ca/).

Custom TaqMan ${ }^{\circ}$ copy numbers assays were acquired from Applied Biosystems $^{\oplus} /$ Life Technologies $^{\oplus}$ (Table 1 ). As an endogenous control, a region with a known number of two copies in a human diploid genome,

*Corresponding author: Rinaldo Wellerson Pereira, SGAN 916 Modulo B, "Bloco C" $2^{\circ}$ Andar, Sala C-207 - Brasilia-DF, Brazil, CEP 70790-160, Tel: +55-61-34487222; Fax: +55-61-3347-4797; E-mail: rinaldo.pereira@catolica.edu.br

Received December 26, 2013; Accepted January 29, 2014; Published January 31,2014

Citation: Jimenez DE, de Lima Lins TC, Taveira PO, Pereira RW (2014) A Prospective Screening of Gene Copy Number Variation in Brazilian Admixed Population Sample. Hereditary Genet 3: 125. doi:10.4172/2161-1041.1000125

Copyright: (c) 2014 Jimenez DE, et al. This is an open-access article distributed under the terms of the Creative Commons Attribution License, which permits unrestricted use, distribution, and reproduction in any medium, provided the original author and source are credited. 
Citation: Jimenez DE, de Lima Lins TC, Taveira PO, Pereira RW (2014) A Prospective Screening of Gene Copy Number Variation in Brazilian Admixed Population Sample. Hereditary Genet 3: 125. doi:10.4172/2161-1041.1000125

Page 2 of 5

\begin{tabular}{|c|c|c|c|c|}
\hline Gene & $A M Y 1$ & PCDHB13 & POLR2J4 & NPEPPS \\
\hline Chromosomal Region & 1p21 & $5 q 31$ & $7 q 22.1$ & $17 q 21$ \\
\hline Gene Location & 104198141 - 104301310 & $140593509-140596993$ & $43980494-44058748$ & $45608444-45700642$ \\
\hline Taqman Assay & Hs07226362_cn & Hs04302687_cn & Hs03649316_cn & Hs03957282_cn \\
\hline Assay Location & 104292504 & 140594945 & 43999812 & 45672783 \\
\hline Median Copy * & 9.49 & 4.01 & 9.75 & 5.97 \\
\hline Variance * & 8.31 & 1.13 & 5.46 & 3.5 \\
\hline Mean European copy * & N.A. & 4.94 & 8.62 & 5.5 \\
\hline Mean Asian copy * & N.A. & 4.42 & 9.53 & 5.42 \\
\hline Mean Yoruba copy * & N.A. & 3.77 & 11.18 & 8.27 \\
\hline Vst * & 0.13 & 0.33 & 0.26 & 0.50 \\
\hline
\end{tabular}

*Sudmant et al. 2010. N.A. = Data not available.

Table 1: Characterization of Genes and assays. Based on Build 37 of the human genome reference.

\begin{tabular}{|c|c|c|c|c|c|c|c|c|}
\hline \multirow{2}{*}{ Copy Number } & \multicolumn{2}{|c|}{ NPEPPS } & \multicolumn{2}{|c|}{$A M Y 1$} & \multicolumn{2}{|c|}{ POLR2J4 } & \multicolumn{2}{|c|}{ PCDHB13 } \\
\hline & $\mathrm{n}$ & $\%$ & $\mathrm{n}$ & $\%$ & $\mathrm{n}$ & $\%$ & $n$ & $\%$ \\
\hline 0 & 0 & - & 0 & - & 0 & - & 0 & - \\
\hline 1 & 1 & $1.0 \%$ & 1 & $1.0 \%$ & 1 & $1.0 \%$ & 1 & $1.0 \%$ \\
\hline 2 & 35 & $36.5 \%$ & 28 & $29.2 \%$ & 84 & $87.5 \%$ & 88 & $91.7 \%$ \\
\hline 3 & 54 & $56.3 \%$ & 38 & $39.6 \%$ & 11 & $11.5 \%$ & 7 & $7.3 \%$ \\
\hline 4 & 1 & $1.0 \%$ & 18 & $18.8 \%$ & 0 & - & 0 & - \\
\hline 5 & 5 & $5.2 \%$ & 7 & $7.3 \%$ & 0 & - & 0 & - \\
\hline 6 & 0 & - & 2 & $2.1 \%$ & 0 & - & 0 & - \\
\hline 7 & 0 & - & 2 & $2.1 \%$ & 0 & - & 0 & - \\
\hline 8 & 0 & - & 1 & $1.0 \%$ & 0 & - & 0 & - \\
\hline
\end{tabular}

Table 2: Absolute and relative percentage frequencies of copy number in 96 individuals of the Brazilian population in the NPEPPS, AMY1, POLR2J4, PCDHB13 genes accessed by qPCR.
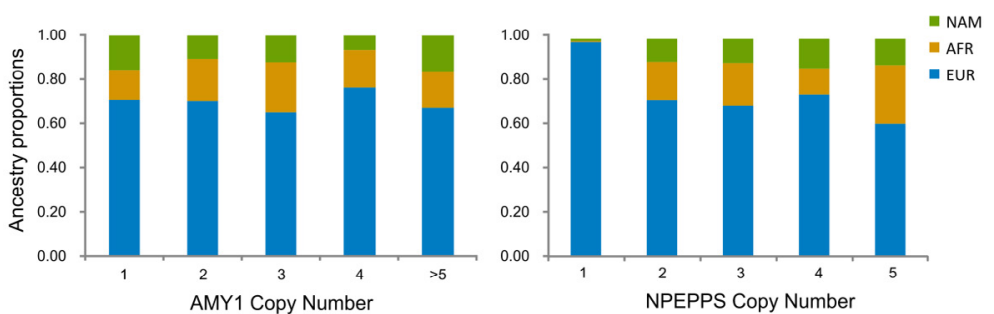

Figure 1: Ancestry proportion estimates differentiated by copy number variation of the AMY1 and NPEPPS genes in 96 individuals of the Brazilian population.

the Ribonuclease P RNA component H1 (H1RNA) gene (RPPH1) on chromosome 14, cytoband 14q11.2, also known as RNAse P, was used as the standard reference assay for the analysis of human copy number. The PCR was performed with a volume reduced validated protocol $[29,30]$ in a 96 well plate. The qPCR were run in a Step One Plus realtime $\mathrm{PCR}^{\oplus}$ (Applied Biosystems) which was configured in accordance to the manufacturer's instructions. The TaqMan ${ }^{\circ}$, the copy number target and the reference assay were performed simultaneously in each reaction. The samples, sample calibrator and negative control were tested in triplicate, and fluorescence signals were normalized to ROX.

\section{Data Analysis}

The copy number of the genes was determined by comparative Cycle threshold (delta-delta-Ct) method, which measured the $\mathrm{Ct}$ difference (delta-Ct) between target and reference assay, and then compared the delta-Ct values of test samples to a known calibrator sample [31]. Primer efficiency was tested and calculated with a four point standard curve using serial dilutions of a pooled DNA sample of high quality and quantity, according to MIQE guideline. Quantification of calculated and predicted copy number were generated from Ct data and analyzed with CopyCaller ${ }^{\circledR}$ softwarev2.0 (Applied Biosystems).
Descriptive statistics of copy number frequency and t-test calculated in SPSS version 13.

\section{Results}

The primer validation was determined by standard curve efficiency and $\mathrm{R}^{2}$ value. A pooled DNA sample from 10 individuals was used with an initial concentration of $500 \mathrm{ng} / \mu \mathrm{L}$ in 1:4 serial dilutions. The efficiency values ranged from $97.19 \%$ to $109.75 \%$ and $\mathrm{R}^{2}$ from 0.993 to 0.996.

The four analyzed regions presented the minor copy number frequency of less than $1 \%$. The CNV-embedded genes were estimated with a mean copy of 2.73 with a respective variance of \pm 0.55 for the NPEPPS gene; $2.10 \pm 0.11$ for POLR2J4; $2.06 \pm 0.08$ for PCDH-B13 and lastly, for the $A M Y 1$ gene, a high polymorphism was observed, represented by a mean of 3.19 copies with a variance of \pm 1.49 , ranging from 1 to 8 copies. (Table 2) shows total and percentage frequencies of copy number variation for NPEPPS, POLR2J4, AMY1 and PCDH-B13 genes in the Brazilian population sample.

Individual proportions of ancestry were previously accessed [28] and estimated as mean \pm standard deviation: $0.702 \pm 0.232$ for 


\begin{tabular}{|c|c|c|c|c|c|c|c|}
\hline \multirow{2}{*}{ Ancestry } & \multirow{2}{*}{ Group } & \multicolumn{3}{|c|}{ NPEPPS } & \multicolumn{3}{|c|}{ AMY1 } \\
\hline & & $\mathrm{n}$ & (Mean \pm Std. Deviation) & $p$-value & $\mathrm{n}$ & (Mean \pm Std. Deviation) & $\mathrm{p}$-value \\
\hline \multirow{2}{*}{ EUR } & Diploid & 35 & $0.718 \pm 0.249$ & \multirow{2}{*}{0.556} & 28 & $0.677 \pm 0.249$ & \multirow{2}{*}{0.457} \\
\hline & Gain & 60 & $0.689 \pm 0.222$ & & 67 & $0.716 \pm 0.225$ & \\
\hline \multirow{2}{*}{ AFR } & Diploid & 35 & $0.175 \pm 0.166$ & \multirow{2}{*}{0.480} & 28 & $0.206 \pm 0.164$ & \multirow{2}{*}{0.468} \\
\hline & Gain & 60 & $0.199 \pm 0.153$ & & 67 & $0.180 \pm 0.157$ & \\
\hline \multirow{2}{*}{ NAM } & Diploid & 35 & $0.107 \pm 0.129$ & \multirow{2}{*}{0.883} & 28 & $0.116 \pm 0.149$ & \multirow{2}{*}{0.693} \\
\hline & Gain & 60 & $0.111 \pm 0.158$ & & 67 & $0.103 \pm 0.146$ & \\
\hline
\end{tabular}

Table 3: Ancestry proportions inNPEPPS and AMY1 genes relative to diploid and gain of copies. T-test was used for comparison of the means between groups with significant $p$-value defined as $<0.05$.

European; $0.189 \pm 0.158$ for African; and $0.109 \pm 0.147$ for Native American ancestry. Albeit the genes were selected by the differences in copy number among continental populations, no significant difference between the percentage of European, African and Native American ancestries were detected within each copy number (Figure 1) and the categories of diploid/Gain of copies (Table 3) for the NPEPPS and $A M Y 1$ genes.

\section{Discussion}

CNVs play some role in instances of phenotypic evolution, and complex diseases [7,11-18]. Changes in the coding sequence of a gene, alterations in expression level and creations of paralogs with new features, represent some mechanisms by which the CNV can produce phenotypic alterations, triggering potential changes of adaptation and function in the affected gene [19,32]. As molecular structure and haplotype configuration of copy number variants cannot be resolved by qPCR methods, we avoided the term allele. As consequence, comparisons of haplotype estimation or genetic diversity were unable to be determined.

The NPEPPS, PCDHB13, POLRJ2 and AMY1 genes were selected from a previous study [7] based on the variance in copy number values among individuals from different populations, i.e. values of Vst (Table 1), especially between European and African population. A Vst close to 1 implies in a considerable degree of differentiation among populations. Inference of population diversity based on CNV often shows higher diversity in African populations than in European populations. Therefore, admixture has the potential to generate spurious association in population genetics studies underlying gene copy number variation $[6,7,11,25,26]$. However, in the Brazilian population, variation occurred at least with $1 \%$ frequency difference and, even though it has exhibited dissimilar frequencies than those previously described for other world continental populations [7], it did not present statistical correlation with genetic ancestry. This fact might bring to question whether there are other forces such as recombination, mutation or selection, which drives the genomic architecture of large variations in population genetics. Further studies with admixed population using read depth sequencing are required to expand the discussion on this topic.

The methods used for detecting and screening CNV are diverse, and some advantages and disadvantages may be associated to the typing and sequencing technologies [33]. CNV calling via read depth sequencing is generally more accurate than via other sequencing data [7]. However, validation by qPCR and/or fluorescence in situ hybridization (FISH), it is necessary to avoid false positive or false negative results from sequencing strategies $[10,12]$. Quantitative PCR has been extensively used to validate copy number alterations in humans. It allows a locusspecific quantitation of genomic DNA using a reference gene within the same individual [31].

A cluster of multiple gene copies located on the short arm of chromosome 1 represents the human amylase gene family. The AMY1 gene codes for the three salivary glands amylases isozymes [34]. Amylase represents 40 to $50 \%$ of salivary protein and catalyzes the first step in the digestion of starch by altering its physical properties in the oral cavity [34]. The variability in different number of copies of the AMYlgene correlates positively with significantly affected the concentration and activity of salivary amylase [34], in which populations with a starchrich diet present more $A M Y 1$ gene copies than those with low starch diets [20]. Therefore, the genetic variation in $A M Y 1$ gene seems to have evolved independently in different populations worldwide, according to the influence on eating habits and nutritional consumption of starch. Several studies observed variations in different human populations ranging from 1 to 15 copy number [7,20,34], with a moderate variance but a low differentiation among continental population samples [7]. The results obtained in the present study had an average of 3.19 copies and ranged from 1 to 8 copies with variance of 1.49 , depicting high variability in the Brazilian population. It is important to mention that the TaqMan ${ }^{\circ}$ assay Hs07226362_cn has 3 genomic targets in NCBI build 37: AMY1A (Chr.1:104198366), AMY1B (Chr.1:104238841) and $A M Y 1 C$ (Chr.1:104292504), thus corresponding to the AMY1 gene cluster instead of a single gene. Hence, the standard TaqMan ${ }^{\circ}$ assay used is not accurate to estimate individual gene copy number variation.

The NPEPPS gene encodes an aminopeptidase sensitive to the puromycin. Considered an enkephalinase, it is abundant in the brain, and some studies suggest that it also plays other roles in the central nervous system (CNS) such as degradation of polyglutamine repeats involved in the pathogenesis of Huntington's disease [35], or as a neuroprotective factor that prevents neurodegeneration induced by TAU protein in Alzheimer's disease [36]. The analyses of 159 genomes from individuals of European, Asian and African ancestry showed this gene as a copy number polymorphism [7]. The previous analysis found a mean copy number of 5.50, 5.42, 8.27 in respective populations and an overall average of 5.97 copies. In addition, a study in 487 DNA samples of individuals from five different populations demonstrated that Africans have more NPEPPS copies than non-Africans [6]. In the present study, the Brazilian sample had an average of 2.73 copies for the NPEPPS gene ranging from 1 to 5 copies, suggesting lower variability of this gene in the Brazilian population compared to others [2,3]. In regard of the applicability of this variability, this gene is a strong candidate to Alzheimer's disease related phenotypes since there are evidences that genetic ancestry is a protective factor for the disease $[37,38]$.

The other two genes PCDHB13 (located on the long arm of chromosome 5 and expressed in the nervous system and proteins directed to the intracellular mature synapses) and POLR2J4 (located on the long arm of chromosome 7 encodes a subunit of RNA polymerase II) presented a high copy number estimated for European, Asian and African populations according to other study [7]. The $P C D H B 13$ gene presented an average copy number of 4.94 in European population, 4.42 in Asian and 3.77 in African, and an overall average of 4.01. .The 
Citation: Jimenez DE, de Lima Lins TC, Taveira PO, Pereira RW (2014) A Prospective Screening of Gene Copy Number Variation in Brazilian Admixed Population Sample. Hereditary Genet 3: 125. doi:10.4172/2161-1041.1000125

Page 4 of 5

POLR2J4 varies in mean copy number from 8.62 in Europeans to11.18 in Yoruba population [7]. However, in the present study it showed respective frequency of $91.7 \%$ and $87.5 \%$ for 2 copies, suggesting low variability of these genes in Brazilian population. A different study showed the PCDHB13 gene with a mean of 2 copies when analyzing samples from African, Asian and European ancestry [6].

The distinct results of the copy number polymorphism for the genes found here in contrast to other studies may be explained by some limiting factors. First of all, the genomic CNV can be detected by two main assessment methods: genome-wide and locus-specific analysis. Historically, comparative genomic hybridization (CGH) and fluorescence in situ hybridization (FISH) were the standard experiments to detect CNVs. However, Chromosomal Microarray Analysis (CMA) and quantitative real-time PCR (qPCR) have taken their place on CNV investigation $[39,40]$. Each method has its own drawbacks. For example, experiments with CMA SNP arrays can be noisy, especially in repetitive regions or regions with complex rearrangements. Added to that, SNP coverage and the number of markers neighboring the genes is not sufficient nor uniformly distributed to have a completely accurate estimation, and thus may generate false positives or negatives results. One way to overcome this situation is to validated experimentally those loci by a qPCR approach $[9,33,41]$, in which drawbacks emphasize accuracy, precision and the use of a validated control sample in each reaction [41]. A unique calibrator sample analyzed in all PCR runs as a way to provide a positive control for every reaction and maintain the quality control during the copy number prediction.

The capture of rare copy number configurations and other variants may require a larger sample size to ensure a representative distribution of CNV over an admixed population. While others stated that $\mathrm{CNV}$ regions previously described have well defined breakpoints [7], and the assays map within the genes delimitation, it cannot be excluded the possibility of any crossing-over rearrangement event occurred throughout the history of Brazilian population, because of its intense admixed heterogeneity, creating de novo breakpoint regions [42].

Since the admixture process has a significant impact on population genetics and there is no prior research on Brazilian population for these genes, this study calls attention to future analysis. Nevertheless, it is necessary upcoming research to use the same genotyping methods and assays to analyze CNVs in European and African populations. It is also important incorporate high-resolution technologies and secondgeneration sequencing to corroborate the copy number polymorphisms in the field of population genetics.

\section{Acknowledgements}

Research supported by the Conselho Nacional de Desenvolvimento Científico e Tecnologico (CNPq) and Coordenação de Aperfeiçoamento de Pessoal de Nível Superior (CAPES) for supporting Graduate scholarships.

\section{References}

1. Feuk L, Carson AR, Scherer SW (2006) Structural variation in the human genome. Nat Rev Genet 7: 85-97.

2. Freeman JL, Perry GH, Feuk L, Redon R, McCarroll SA, et al. (2006) Copy number variation: new insights in genome diversity. Genome Res 16: 949-961.

3. Levy S, Sutton G, Ng PC, Feuk L, Halpern AL, et al. (2007) The diploid genome sequence of an individual human. PLoS Biol 5: e254.

4. Wheeler DA, Srinivasan M, Egholm M, Shen Y, Chen L, et al. (2008) The complete genome of an individual by massively parallel DNA sequencing. Nature 452: 872-876

5. Schrider DR, Hahn MW (2010) Gene copy-number polymorphism in nature. Proc Biol Sci 277: 3213-3221.

6. Campbell CD, Sampas N, Tsalenko A, Sudmant PH, Kidd JM, et al. (2011)
Population-genetic properties of differentiated human copy-number polymorphisms. Am J Hum Genet 88: 317-332.

7. Sudmant PH, Kitzman JO, Antonacci F, Alkan C, Malig M, et al. (2010) Diversity of human copy number variation and multicopy genes. Science 330: 641-646.

8. Conrad DF, Andrews TD, Carter NP, Hurles ME, Pritchard JK (2006) A highresolution survey of deletion polymorphism in the human genome. Nat Genet 38: 75-81.

9. Cooper GM, Zerr T, Kidd JM, Eichler EE, Nickerson DA (2008) Systematic assessment of copy number variant detection via genome-wide SNP genotyping. Nat Genet 40: 1199-1203.

10. lafrate AJ, Feuk L, Rivera MN, Listewnik ML, Donahoe PK, et al. (2004) Detection of large-scale variation in the human genome. Nat Genet 36: 949951.

11. McCarroll SA, Kuruvilla FG, Korn JM, Cawley S, Nemesh J, et al. (2008) Integrated detection and population-genetic analysis of SNPs and copy number variation. Nat Genet 40: 1166-1174.

12. Sebat J, Lakshmi B, Troge J, Alexander J, Young J, et al. (2004) Large-scale copy number polymorphism in the human genome. Science $305: 525-528$.

13. de Smith AJ, Tsalenko A, Sampas N, Scheffer A, Yamada NA, et al. (2007) Array $\mathrm{CGH}$ analysis of copy number variation identifies 1284 new genes variant in healthy white males: implications for association studies of complex diseases. Hum Mol Genet 16: 2783-2794.

14. Redon R, Ishikawa S, Fitch KR, Feuk L, Perry GH, et al. (2006) Global variation in copy number in the human genome. Nature 444: 444-454.

15. Beckmann JS, Estivill X, Antonarakis SE (2007) Copy number variants and genetic traits: closer to the resolution of phenotypic to genotypic variability. $\mathrm{Na}$ Rev Genet 8: 639-646.

16. Hastings PJ, Lupski JR, Rosenberg SM, Ira G (2009) Mechanisms of change in gene copy number. Nat Rev Genet 10: 551-564.

17. Satoh Y, Sasaki K, Shimoichi Y, Sugita K, Katayama H, et al. (2012) Copynumber variations observed in a Japanese population by BAC array $\mathrm{CGH}$ : summary of relatively rare CNVs. J Biomed Biotechnol 2012: 789024

18. Stranger BE, Forrest MS, Dunning M, Ingle CE, Beazley C, et al. (2007) Relative impact of nucleotide and copy number variation on gene expression phenotypes. Science 315: 848-853.

19. Nguyen DQ, Webber C, Ponting CP (2006) Bias of selection on human copynumber variants. PLoS Genet 2: e20.

20. Perry GH, Dominy NJ, Claw KG, Lee AS, Fiegler H, et al. (2007) Diet and the evolution of human amylase gene copy number variation. Nat Genet 39 1256-1260.

21. Conrad DF, Hurles ME (2007) The population genetics of structural variation Nat Genet 39: S30-36

22. Li J, Yang T, Wang L, Yan H, Zhang Y, et al. (2009) Whole genome distribution and ethnic differentiation of copy number variation in Caucasian and Asian populations. PLoS One 4: e7958.

23. Wong KK, deLeeuw RJ, Dosanjh NS, Kimm LR, Cheng Z, et al. (2007) A comprehensive analysis of common copy-number variations in the human genome. Am J Hum Genet 80: 91-104.

24. Zhang YB, Li X, Zhang F, Wang DM, Yu J (2012) A preliminary study of copy number variation in Tibetans. PLoS One 7: e41768.

25. Armengol L, Villatoro S, González JR, Pantano L, García-Aragonés M, et al. (2009) Identification of copy number variants defining genomic differences among major human groups. PLoS One 4: e7230.

26. Pronold M, Vali M, Pique-Regi R, Asgharzadeh S (2012) Copy number variation signature to predict human ancestry. BMC Bioinformatics 13: 336 .

27. Lins TC, Vieira RG, Abreu BS, Gentil P, Moreno-Lima R, et al. (2011) Genetic heterogeneity of self-reported ancestry groups in an admixed Brazilian population. J Epidemiol 21: 240-245.

28. Lins TC, Vieira RG, Abreu BS, Grattapaglia D, Pereira RW (2010) Genetic composition of Brazilian population samples based on a set of twenty-eight ancestry informative SNPs. Am J Hum Biol 22: 187-192.

29. Manta FS, Pereira R, Caiafa A, Silva DA, Gusmão L, et al. (2013) Analysis of genetic ancestry in the admixed Brazilian population from Rio de Janeiro using 46 autosomal ancestry-informative indel markers. Ann Hum Biol 40: 94-98. 
Citation: Jimenez DE, de Lima Lins TC, Taveira PO, Pereira RW (2014) A Prospective Screening of Gene Copy Number Variation in Brazilian Admixed Population Sample. Hereditary Genet 3: 125. doi:10.4172/2161-1041.1000125

Page 5 of 5

30. Mayo P, Hartshorne T, Li K, McMunn-Gibson C, Spencer K, et al. (2010) CNV analysis using TaqMan copy number assays. Curr Protoc Hum Genet Chapter 2: Unit2.

31. Schmittgen TD, Livak KJ (2008) Analyzing real-time PCR data by the comparative C(T) method. Nat Protoc 3: 1101-1108.

32. Schlattl A, Anders S, Waszak SM, Huber W, Korbel JO (2011) Relating CNVs to transcriptome data at fine resolution: assessment of the effect of variant size, type, and overlap with functional regions. Genome Res 21: 2004-2013.

33. Curtis C, Lynch AG, Dunning MJ, Spiteri I, Marioni JC, et al. (2009) The pitfalls of platform comparison: DNA copy number array technologies assessed. BMC Genomics 10: 588

34. Mandel AL, Peyrot des Gachons C, Plank KL, Alarcon S, Breslin PA (2010) Individual differences in AMY1 gene copy number, salivary $\hat{I} \pm$-amylase levels, and the perception of oral starch. PLoS One 5: e13352.

35. Bhutani, N., P. Venkatraman, and A.L. Goldberg (2007) Puromycin-sensitive aminopeptidase is the major peptidase responsible for digesting polyglutamine sequences released by proteasomes during protein degradation. EMBO J. 26: 1385-96.

36. Karsten SL, Sang TK, Gehman LT, Chatterjee S, Liu J, et al. (2006) A genomic screen for modifiers of tauopathy identifies puromycin-sensitive aminopeptidase as an inhibitor of tau-induced neurodegeneration. Neuron 51: 549-560.

37. Benedet AL, Moraes CF, Camargos EF, Oliveira LF, Souza VC, et al. (2012) Amerindian genetic ancestry protects against Alzheimer's disease. Dement Geriatr Cogn Disord 33: 311-317.

38. Schlesinger D, Grinberg LT, Alba JG, Naslavsky MS, Licinio L, et al. (2013) African ancestry protects against Alzheimer's disease-related neuropathology. Mol Psychiatry 18: 79-85.

39. Li W, Olivier M (2013) Current analysis platforms and methods for detecting copy number variation. Physiol Genomics 45: 1-16.

40. Breckpot J, Thienpont B, Arens Y, Tranchevent LC, Vermeesch JR, et al (2011) Challenges of interpreting copy number variation in syndromic and nonsyndromic congenital heart defects. Cytogenet Genome Res 135: 251-259.

41. Lee JH, Jeon JT (2008) Methods to detect and analyze copy number variations at the genome-wide and locus-specific levels. Cytogenet Genome Res 123 333-342.

42. Kidd JM, Sampas N, Antonacci F, Graves T, Fulton R, et al. (2010) Characterization of missing human genome sequences and copy-number polymorphic insertions. Nat Methods 7: 365-371. 